continued to be used by archæologists and others, and utilization of the Bureau's photographic collections increased.

The Astrophysical Observatory continued its researches in solar astrophysics as well as its meteorite studies, greater emphasis being given to the broader scientific investigation of phenomena in the solar system, and stress is laid on the Observatory's 'Moonwatch' programme-the optical tracking of the Earth satellites launched as part of the International Geophysical Year. Careful statistical studies were made of the variation of solar radiation intensity ; theoretical studies were made of the propagation of non-adiabatic acoustic waves in the solar atmosphere, and the theory of non-steady phenomena in the solar atmosphere and corona was investigated. The study of the ablation of meteorites was concerned with the distinct shapes and surface features of meteorites and the examination of the internal structure from a metallurgical point of view.

The Division of Radiation and Organisms continued its work on the role of light in regulating growth in plants, including photomorphogenesis, phototropism, chloroplast development, photoperiodic chlorosis, and the modification of $\mathrm{X}$-ray damage by visible radiant energy.

During the year, 1,050 specimens were added to the National Air Museum, and increasing requests are being received for information on aeronautical history and progress. Accessions to the National Zoological Park, which covers 176 acres, numbered 1,851 , but 2,965 were removed by death, exchange or return to depositors, and the net count at the close of the year was 3,157. Visitors are estimated at almost four million. Although veterinary work was curtailed, a co-operative study was undertaken on aspergillosis in birds to determine the best method of artificial infection and the mode of natural transmission, to develop a sensitivity test or other method for early diagnosis, and to discover the most efficacious method of treatment.

Visitors to Barro Colorado Island totalled 750 , including sixty-one scientists using the station's facilities of special researches, particularly in observation of wild fowl, forest ecology, photography and studies of insects. The International Exchange Service handled 1,205,039 packages of Government, scientific and literary publications, an increase of 43,184 on the previous year. The Smithsonian Library received 54,316 publications during the year ; 1,110 volumes were issued on inter-library loans to 116 Government and other libraries throughout the country, and 13,000 reference questions were answered. Eighty new Smithsonian publications were issued during the year and 405,266 copies of publications and miscellaneous items were distributed.

\title{
THE NATIONAL SCIENCE FOUNDATION
}

$\mathrm{T}$ HE seventh annuel report of the National Science Foundation for the year ended June 30, 1957*, includes a foreword from the chairman of the National Science Board, Dr. D. W. Bronk, and the Director's statement, to which are appended the financial report, particulars of membership of the Board, its staff, committees and advisory panels, lists of publications and of research grants and fellowship awards. The programme activities of the Foundation, on which expenditure was 664,561 dollars, included a continued survey of the United States effort in research and development, most of the initial series of studies for which were completed during the year. A further survey of the industry sector for 1955 and 1956 is now being conducted. The report also summarizes the findings of a survey of Federal financial support of research facilities and equipment, which recommended that while Federal support for operation and management is sometimes unavoidable, ideally it should be confined to establishment and construction costs and conditional on participation by recipient institutions and other bodies concerned and on the availability of competent scientific man-power.

An advisory panel on the status of high-energy nuclear research in the United States recommended that the U.S. Government should continue its active support of high-energy physies, including the design, construction and operation of, and experiment with, high-energy accelerators ; in particular, extension of the support given by the Department of Defence and the National Science Foundation was recommended. Expenditure on high-energy accelerators is estimated to reach 60-90 million dollars a year by 1962 and

- National Science Foundation, Washington. Seventh Annual Report for the Fiscal Year ended June 30, 1957. Pp. xix +279. this level is believed to be essential. The need for accelerators of varied types should be recognized, the most important parameters being energy, intensity and kind of particle, and it is usually preferable to extend the range of these parameters rather than to increase the number of functionally similar accelerators. Research and development on new types of accelerators should be adequately supported, and especially efforts should be made to increase the energy limit. Proposals for the location of new accelerators should be reviewed on their merits, having regard to the research contemplated, the stimulus to science and the opportunities for training. An Advisory Committee on Minerals Research through various subcommittees concluded that much new co-ordinated research was required in geology, geochemistry and geophysics to pursue mineral exploitation scientifically. To determine the scale, distribution and character of this research, all existing data on mining districts should first be re-examined and synthesized to avoid duplication of effort or omission of fundamential studies. This programme requires the continuing participation of all existing agencies; the establishment of a Minerals Research Institute was also recommended, to conduct, co-ordinate and assimilate fundamental research in fields of science related to the formation of mineral deposits and disseminate the results of such research activities. This Institute should be supported and maintained largely by the mining companies. During the year the Foundation completed the transfer to the Office of Technical Services of the Department of Commerce of all research and development reports on synthetic rubber. The Foundation reported favourably on a proposal to establish a geophysical institute as part of the University of Hawaii, but Federal funds should 
be conditional on adequate research potential in the supporting science departments and on adequate local support.

Grants for biological and medical research numbered 527 and totalled 7,620,925 dollars. Among the significant research developments noted in the report are the breaking of summer dormancy in tomatoes by spreying with gibberellic acid; the discovery that the unicellular organism, the dinoflagellate Gonyaulax polyedra responsible for oceanic luminescence, emits light rhythmically - as much as sixty times brighter at night than by day; the discovery that N-1-naphthylphthalamic acid prevents the differential growth of plants under gravity; and of a new metabolic pathway in mammals by the study of congenital pentosuria. Investigations into the physiology of insect feeding, the structure of proteins, the changes in electrical activity accompanying the learning process, the environmental factors involved in determining the success of insect reproduction, the mechanism underlying the induction of mutations, the relation between age of father and sex of offspring, the factors involved in embryonic limb development and the sequential development of embryonic tissue development have also yielded significant results; grants for facilities totalled 885,000 dollars. Grants for research in mathematical, physical and engineering sciences numbered 997 and totalled 7,908,000 dollars, with a further 4 million dollars for construction of a radio-astronomical observatory at Greenbank, West Virginia, 500,000 dollars to the Massachusetts Institute of Technology towards a 2 million watt nuclear reactor and 545,000 dollars to the University of Michigan for studies leading to the establishment of an optical astronomical observatory. Results from Foundation grants noted in the report include a new scanning spectrograph, the determination of the structure of the antibiotic, magnamycin, a portable instrument for directly measuring the water content of clouds, and a new cosmic ray telescope.

In support of travel to international scientific meetings, 205 grants totalling 118,286 dollars were made, and support was given to 25 scientific conferences, including the fifteenth and sixteenth Growth Symposia, the sixth International Congress of Hæmatology, an International Conference on Theoretical Physics at the University of Washington, the Midwest Conference on Theoretical Physics, the seventh Annual Conference on High-Energy Nuclear Physics, the third International Conference on Irrigation and Drainage, the third Symposium on Cosmical Gas Dynamies, the International Conference on Audiology, the twenty-second Cold Spring Harbor Symposium on Quantitative Biology, and others on binary stars, radiocarbon dating, the size and shape of the Earth, gravitational theory, asphyxia neonatorum brain damage and impairment of learning in experimental animals, the role of botany in American education, cellular and humoral aspects of hypersensitive states, archæological identification by specialists in related disciplines, ageing as a biological problem, the scale of the galaxy, nuclear geophysics, the structure of electrolyte solutions and problems of tektites.

On graduate fellowships the Foundation in 1957 expended 3,353,605 dollars, including fellowship awards to 845 applicants, 109 postdoctoral awards, 55 senior postdoctoral fellowships and 100 science faculty fellowships. An evaluation of fellowship selection methods indicated a parallel between the subsequent careers of unsuccessful applicants and their ability as judged by the evaluation panels, and that lack of financial support was the primary reason why a substantial percentage of students of graduate school calibre failed to continue their education. A complete statistical analysis of the 125,000 scientists on the National Register of Scientific and Technical Personnel was commenced and under the Clearing House Programme pilot surveys of demand for engineers in selected industries and of short-term demand for scientists and engineers were initiated as well as surveys of the training of high-school teachers of science and mathematics by the U.S. Office of Education and of the assessment of scientific talent by the University of Chicago. Attendance at the 96 summer institutes supported by the Foundation exceeded 5,300 teachers; at the 16 academic-year institutes 775 teachers will be trained in the 1957-58 programme and approximately 850 are expected to attend the 21 new In-Service Institutes for training in supplementary subjects for science and mathematics teachers commenoing in the autumn of 1957. Curricula studies included the development of a new curriculum in physics for high schools. The Foundation also opersted jointly with the American Association for the Advancement of Science the Travelling Science Library Programme, and with the Atomic Energy Commission the Travelling Science Demonstration Lecture Programme. Besides various teacher-training projects, the Foundation gave increasing attention to the evaluation of its experimental activities such as the summer institutes programme and the visiting scientists programme.

The emphasis of the Foreign Science Information Programme is at present almost exclusively on Russian scientific literature, and grants to the American Geophysical Union and the American Institute of Biological Studies, while continuing support of translations by the American Institute of Physics, increased the journal translation programme in effect to nine, while grants were also made for translating two Russian monographs in biology and one in physical chemistry and to Biological Abstracts for continuing to translate about 2,400 Russian abstracts a year. The Government Research Information Programme includes grants to the Office of Technical Services, Department of Commerce, towards a report abstracting service ; to the Science Division, Library of Congress, for a reference collection of unclassified science reports on basic research ; and for a clearing house within the Foundation for scientists seeking information on Government scientific research, which has already handled 695 inquiries.

Under the Scientific Documentation Programme, the Foundation is supporting a study of the feasibility of using a formal linguistic method of analysis to simplify the sentence structure of scientific tests in processing them for mechanized information storage; an analysis of words and phrases in scientific documents leading to the demonstration of a possible system for mechanized information searching, which would use a regularized English; and research on machine translation at three institutions. A conference of editors of biological journals supported by the Foundation resulted in the estab. lishment of a continuing annual conference to review reports of committees examining specific publication problems, and the American Institute of Physics was assisted in the preparation of a manual for authors of papers to be published in physics journals. Emergency support was afforded to several scientific periodicals. 